\title{
Therapeutic Vaccines Against Human Papilloma Viruses: Achievements and Prospects
}

\author{
M. S. Vonsky ${ }^{1,2, a}$, A. L. Runov ${ }^{1,2,3}$, I. V. Gordeychuk ${ }^{3,4,5, b}$, and M. G. Isaguliants ${ }^{3,4,6,7, c *}$ \\ ${ }^{1}$ Institute of Cytology, Russian Academy of Sciences, 194064 St. Petersburg, Russia \\ ${ }^{2}$ Almazov National Medical Research Centre, Ministry of Health of Russian Federation, 197341 St. Petersburg, Russia \\ ${ }^{3}$ Gamaleya National Research Center for Epidemiology and Microbiology, \\ Ministry of Health of Russian Federation, 123098 Moscow, Russia \\ ${ }^{4}$ Chumakov Federal Scientific Center for Research and Development of Immune-and-Biological Products, \\ Russian Academy of Sciences, 108819 Moscow, Russia \\ ${ }^{5}$ Sechenov First Moscow State Medical University, Ministry of Health of Russian Federation, 119991 Moscow, Russia \\ ${ }^{6}$ Karolinska Institutet, Department of Microbiology, Tumor and Cell Biology, SE-171 77 Stockholm, Sweden \\ ${ }^{7}$ Riga Stradins University, Department of Pathology, LV-1007 Riga, Latvia \\ ${ }^{a} e$-mail:m.vonsky@gmail.com \\ ${ }^{b}$ e-mail: lab.gord@gmail.com \\ ${ }^{c} e$-mail: maria.issagouliantis@rsu.lv
}

Received April 3, 2019

Revised April 15, 2019

Accepted April 21, 2019

\begin{abstract}
Human papillomaviruses of high carcinogenic risk (HR HPVs) are major etiological agents of malignant diseases of the cervix, vulva, penis, anal canal, larynx, head, and neck. Prophylactic vaccination against HPV, which mainly covers girls and women under 25, does not prevent vertical and horizontal HPV transmission in infants and children and does not have a therapeutic effect. As a result, a significant proportion of the population is not protected from the HPV infection and development of HPV-associated neoplastic transformation and cancer, which indicates the need for development and introduction of therapeutic HPV vaccines. Unlike prophylactic vaccines aimed at the formation of virus-neutralizing antibodies, therapeutic vaccines elicit cellular immune response leading to the elimination of infected and malignant cells expressing viral proteins. The ideal targets for vaccine immunotherapy are highly conserved HR HPV oncoproteins E6 and E7 expressed in precancerous and tumor tissues. Here, we describe expression of these proteins during different stages of HPV infection, their antigenic and immunogenic properties, and T-cell epitopes, the response to which correlates with natural regression of HPV-induced neoplastic changes. The review describes patterns of E6 and E7 oncoproteins presentation to the immune system as components of candidate vaccines along with the results of the most promising preclinical trials and animal models used in these trials. Special attention is paid to vaccine candidates which have shown efficacy in clinical trials in patients with HPV-associated neoplastic changes.
\end{abstract}

DOI: $10.1134 / \mathrm{S} 0006297919070101$

Keywords: human papillomavirus, squamous cell carcinoma, neoplasia, E6 and E7 oncoproteins, therapeutic vaccination, genetic vaccines, immune response

Prophylactic vaccination against human papillomavirus (HPV) prevents up to $90 \%$ HPV infections and serves as a powerful tool for protection against HPVassociated neoplastic changes [1, 2]. HPV vaccination was recommended by WHO for the introduction into mandatory vaccination programs 10 years ago (in 2009) and is currently included into national vaccination schedules in 60 countries of the world [3]. It has already

Abbreviations: APC, antigen-presenting cell; CC, cervical cancer; CTL, cytotoxic T-lymphocyte; DC, dendritic cell; HLA, human leukocyte antigen, a group of histocompatibility antigens; HR HPV, human papillomavirus of high carcinogenic risk; HSIL, high grade squamous intraepithelial lesion; ICI, immune checkpoint inhibitor; LLO, listeriolysin O; LSIL, low-grade squamous intraepithelial lesion; MHC, main histocompatibility complex; MVA, modified vaccinia virus Ankara; ORF, open reading frame; SCCHN, squamous cell carcinoma of the head and neck; SFV, Semliki Forest virus; SLPs, long (including overlapping) synthetic peptides; TAA, tumor associated antigen; TCR, T-cell receptor; TLR, toll-like receptor.

* To whom correspondence should be addressed. 
reduced the incidence of anogenital condylomas and precancerous changes of the cervix in Australia, Germany, Sweden, and the United States, which where the first countries to introduce mandatory vaccination programs [1, 2].

Inclusion of HPV vaccination into the state-funded vaccination programs requires substantial budgetary resources. One dose of vaccine preparation costs $\sim 100$ US dollars; vaccination requires three doses and additional expenses for organization of the process. For these reasons, it is hard to expect a significant increase in the HPV vaccination coverage, especially in the developing countries. In addition, in most countries, which have adopted the mandatory HPV vaccination programs, this applies only to girls and women under 25 years old, while boys and young men are covered by vaccination only in six countries [2]. It is assumed that they will be sufficiently protected by herd immunity. This is not a common opinion; many adhere to the neutral approach to vaccination implying equal inclusion of boys and young men into the program. In addition to sexual transmission of HPV, there is vertical and horizontal transmission to infants and children before they reach the age of vaccination [4]. This makes global eradication of HPV infection through vaccination unrealistic in the near or distant future. This means that a significant proportion of the population is currently not protected and will not be protected from HPV infection and HPV-associated neoplastic changes and cancer.

Moreover, prophylactic HPV vaccines do not have a therapeutic effect, i.e., do not prevent the development of neoplasia in those infected with HPV before the vaccination [1]. Early detection, treatment, and elimination of neoplastic tissues can prevent cancer development in these patients $[5,6]$. However, statistics for the Russian Federation shows that in $18.8 \%$ and $20.2 \%$ cases, cancers are detected only at stages III and IV, respectively, which leads to a high level of mortality in the first year after the diagnosis [7]. Therapeutic vaccination could be one of the potentially effective treatments for HPV-associated cancer [5, 8]. The first success of therapeutic anti-cancer vaccines has been achieved specifically in the treatment of precancerous conditions caused by infection with HPV types 16 and $18[9,10]$. Unlike prophylactic vaccines aimed at the formation of virus-neutralizing antibodies, therapeutic vaccines stimulate cellular immune response resulting in the clearance of infected and malignant cells expressing viral proteins. Clinical trials by Trimble et al. [9] showed that immunotherapy can be an important component of comprehensive programs of cancer treatment, complementing surgery, radiation therapy, and chemotherapy [10]. This necessitates extensive efforts aimed at the development and introduction of therapeutic vaccines against HPV and HPV-associated neoplasia.

\section{PROTEIN TARGETS OF THERAPEUTIC HPV VACCINES}

Prophylactic vaccines should induce humoral immune response capable of neutralizing the virus before it enters the cell. All currently existing prophylactic HPV vaccines induce specific neutralizing antibodies to the $\mathrm{L} 1$ major capsid protein [11]. Unlike prophylactic vaccines, therapeutic vaccines induce $\mathrm{T}$-cell cytotoxicity to eliminate virus-infected cells. The absence of L1 and L2 proteins in many malignant cells due to the deletion of the open reading frames (ORFs) encoding early E1, E2, E4, and $\mathrm{E} 5$ and late $\mathrm{L} 1$ and $\mathrm{L} 2$ proteins makes these antigens unsuitable as targets of therapeutic vaccines against HPVassociated cancer.

The ideal targets for therapeutic vaccines are E6 and E7 oncoproteins [12]. Their increased expression is a necessary and sufficient condition for immortalization and malignant transformation of cells [13-17]. HPV integration, during which the E2 ORF is lost, removes restrictions on their expression and promotes malignancy [18]. Mice transgenic for E6 and/or E7 show histopathological signs of HPV 16 infection, including formation of the benign and malignant papillomas and epitheliomas and development of grade I, II, and III epidermoid carcinomas spontaneously and in the presence of carcinogens $[19,20]$. In addition to the direct carcinogenic effect, expression of E6 and E7 induces the synthesis and release of specific proinflammatory cytokines and chemokines, creating the proinflammatory microenvironment which promotes tumor growth and simultaneously suppresses the antitumor immune response [21]. Importantly, both E6 and E7 are highly conserved. Analysis of genomic sequences of viruses isolated from precancerous and cervical cancer (CC) tissues demonstrated high conservation of the $\mathrm{E} 7$ sequence as opposed to the high variability of the HPV genome in infected individuals without precancerous changes [22].

The unique carcinogenic properties of E6 and E7, their constitutive expression in the pre-cancerous and tumor tissues and sequence conservation make these proteins ideal targets for vaccine immunotherapy of the HPV-associated pre-cancerous conditions and cancer. The protein sequence conservation opens up the possibility of making such vaccines universal, at least for the viruses belonging to the same HR HPV type.

\section{IMMUNOGENIC PROPERTIES OF E6 AND E7 PROTEINS}

Unlike other tumor-associated antigens (TAAs) considered as candidates for anti-cancer vaccines, neither E6 nor E7 are autoantigens. They are immunogenic, do not induce autoimmunity and do not cause tolerance. Before creating an immunotherapeutic HPV vaccine, it is necessary to characterize the natural immunogenicity of 
E6 and E7, i.e., the specific immune response to these oncoproteins in healthy HPV-infected and uninfected individuals, and in patients with HPV-associated neoplasia of different grades. This allows to map protein regions (epitopes) recognized by the immune system and to determine the effect of the immune response to these epitopes on the course of chronic HPV infection. Special emphasis should be placed on the induction of T-cell immune response against HR HPV oncoproteins.

In order to stimulate the response of cytotoxic $\mathrm{CD} 8^{+}$ or helper $\mathrm{CD}^{+} \mathrm{T}$ cells, E6 and E7 antigens have to be presented by the class I or II major histocompatibility complex (MHC) molecules on the surface of antigenpresenting cells (APCs), respectively. For this, E6 and E7 antigens must be processed, i.e., hydrolyzed to peptide fragments by the proteasome $\left(\mathrm{CD}^{+}\right)$or lysosomes $\left(\mathrm{CD}^{+}\right)$. Of these fragments, only a fraction will bind to the MHC molecules with a high affinity and interact with peptide-recognizing receptors of specific T cells (TCRs).

Information on the epitope mapping of antigens of various HPV types is presented on the proteome resource website http://cvc.dfci.harvard.edu/hpv. This resource maintains a database of T-cell epitopes and can be used as a convenient source of information on currently known epitopes and their restriction to the ligands of human leukocyte antigens (HLAs). It can also be used as a platform for predicting new immune targets [23]. Analysis of the data shows that during persistent HPV infection, the immune response is focused on the epitopes of E6 and E7 proteins. Indeed, studies of the T-cell response to peptides from the L1, E6, and E7 proteins by the IFN- $\gamma$ ELISPOT method in women with various stages of HPV infection, including 30 cases of invasive $\mathrm{CC}$, showed that the response against $\mathrm{L} 1$ was observed in subjects with transient HPV infection, while the response against E6 and E7 was found mainly in women with cervical neoplasia [24].

As shown in in vitro tests, a number of E6 and E7 peptides are recognized by $\mathrm{CD} 8^{+}$cytotoxic $\mathrm{T}$ lymphocytes (CTLs) of healthy HPV-infected and uninfected individuals and patients with HPV-associated neoplasia (CTL epitopes). Several studies have shown wide repertoire and promiscuity of these peptides, i.e., low degree of restriction of recognition with respect to the HLA type [25-27]. Despite this, the E6 and E7 peptides epitopes are poorly recognized by the immune system of the patients with HPV-associated neoplasia and cancer. The proportion of individuals with different types of neoplastic changes (including CC) whose immune system recognized the above-described CTL epitopes was extremely low in comparison to the patients with transient HPV infection [24]. The detectable cytotoxic and T-helper cellular response against HPV oncoproteins in individuals with chronic HPV infection and HPV-associated neoplastic changes were of low level. A study of immunoreactivity of T lymphocytes infiltrating the tumor and lymph nodes draining the tumors showed that although up to $66 \%$ of them recognized epitopes of the E6 and E7 oncoproteins; only single cells, when stimulated with E6 and E7 peptides, were able to produce IFN- $\gamma$, which indicates their nonfunctionality [26]. Moreover, CTL clones specific for the E6 epitopes were unable to recognize E6 expressed by E6(+) cervical carcinoma cells, even when the content of E6 was artificially increased by transient transfection [28]. This inability was associated with defects in the epitope representation by carcinoma cells due to the low expression of the surface HLA molecules, subunits of the LMP2 and LMP7 proteasomes, and of the TAP1 and TAP2 transporters [28]. This phenomenon manifested itself regardless of the level of oncogene expression and degree of neoplastic changes [24]. As a result, HPV-transformed cells already at the early stages of their "life" do not present viral antigens to the immune system and do not induce or support natural antiviral immune response. At the same time, patients with spontaneous recession of HPV-associated neoplasia demonstrate the presence of HPV-specific CTLs and T-helper immune response [25, 27, 29]. Overall, the obtained data show that E6 and E7 are immunogenic, but the immune response to them in patients with persistent HPV infection is compromised, which, once again, suggests feasibility of therapeutic HPV vaccination aimed at the induction and/or restoration of the immune response against HR HPV oncogenes.

Naturally, the question arises about the possibility of creating a therapeutic HPV vaccine which would ensure formation of the cross-reactive immune response recognizing several types of HR HPV. A study on the peripheral $\mathrm{CD}^{+} \mathrm{T}$ lymphocytes of healthy individuals vaccinated or not vaccinated against HPV 16 showed that the immune system in $\sim 50 \%$ of these individuals recognized homologous E6 peptides from two or more HPV types [30], which suggests a cross-reactive immune response. However, the history of abortive and transient infections with different types of HPV cannot be excluded. An extensive study using enriched and clonal $\mathrm{T}$ cell cultures and protein antigen instead of peptides revealed that $\mathrm{CD}^{+} \mathrm{T}$ cells which can efficiently recognize E6 of various HPV types are rare, with only highly conserved parts of E6 being cross-recognized [30]. Similar data was obtained by other researchers [31]. Thereby, the T-cell immune response induced by a therapeutic vaccine based on HPV 16 is unlikely to provide efficient cross-protection against other HR HPVs, even those belonging to the same phylogenetic clade. To ensure the therapeutic effect, vaccination should be carried out by immunogens representing the HPV type which caused neoplastic changes.

\section{MODELS FOR TESTING THERAPEUTIC HPV VACCINES}

Studies of the immune response, both innate and specific, in the context of vaccine development require 
the use of surrogate preclinical laboratory animal models. There are several HPV infection models available to the research community. The older, well-characterized models include dog, cow, and rabbit papilloma viruses; the new rodent model have been also developed. All these preclinical models have their strengths and weaknesses and differ in the ability to adequately (in terms of the expected results when used in clinic) predict the development of malignant neoplasias and possibility of therapeutic/immunotherapeutic control of papillomavirus infections [32]. The development of immunotherapeutic HPV vaccines based on immunogens from the animal papillomaviruses (cows, dogs, rabbits, mice), even as recombinants with human HPV, and their testing in relevant animal models can prove the fundamental possibility of this approach, but do not allow preclinical testing of a human vaccine candidate before its clinical trials. For this purpose, the only suitable models are those which allow direct testing of the efficacy of immunogens. Human HPV infection is most closely reproduced in transgenic mice and tumor models based on xenografting into mice of tumors expressing HR HPV antigens. Such tumor models have been successfully used in testing of various immunotherapeutic approaches for treatment of HPVassociated diseases (including cancer) [33], development of strategies of improved antigen presentation [34], elucidation of the role of $\mathrm{CD}^{+} \mathrm{T}$ cells in controlling tumor growth [34, 35], evaluation of the efficacy of immunotherapy with cell cycle immune control inhibitors (ICIs) in preventing T cell depletion [36, 37], and in the development of therapeutic vaccines $[38,39]$.

\section{MAIN APPROACHES TO THE DESIGN OF HPV VACCINES}

To date, many prototypes of therapeutic anti-cancer vaccines based on HR HPV oncoproteins have been developed, the most successful ones have passed clinical trials. These are cell vaccines and vaccines using live vectors, proteins, synthetic peptides and nucleic acids. Most of them, in one form or another, represent E6 and E7 oncoproteins and ensure their delivery to the APCs to stimulate presentation of antigens in the context of MHC class I and II molecules, inducing $\mathrm{CD} 8^{+}$and $\mathrm{CD} 4^{+} \mathrm{T}$-cell immune response. Most candidate vaccines are targeted against E7, which had been better characterized in preclinical studies, although it was found that spontaneous elimination of HR HPV infection correlates to the immune response against E6, rather than E7 [40]. The main approaches currently used in the development of therapeutic vaccines and the mechanisms involved in the induction of specific T-cell immune response are presented in table. The table includes various forms of immunogens representing E6 and/or E7 proteins of HR HPV (mainly, HPV 16), such as live vector vaccines, pep- tides, proteins, plasmid DNA, as well as therapeutic vaccines based on autologous cells, their pros and cons, and examples of their clinical use.

Genetic vaccines, either based on the naked DNA or RNA, or live vectors carrying these DNA or RNA, deliver vaccine antigens to the host cells, including APCs, which ensures their enhanced immunogenicity. Unlike naked DNA and RNA vaccines, live vaccines based on certain bacterial and viral vectors can replicate in recipient cells, thereby renewing their genetic material and maintaining a high level of synthesis of vaccine antigens (immunogens). These vaccine variants are especially attractive because they can induce an immune response similar to the one induced in the natural infection resulting in elimination of the pathogen. Particularly interesting are the results of the phase II clinical trials of vaccine preparations based on modified vaccinia viruses expressing HPV 16 E6, HPV 16 E7, HPV 18 E6, or HPV 18 E7 [41], as well as DNA vaccines based on E6 and E7 of HPV 16 and 18 (VGX-3100) in patients with severe vaginal or uterine intraepithelial neoplasia $[9,10,42]$. Both types of vaccines caused persistent regression of lesions in more than $40 \%$ participants, which confirms the therapeutic potential of genetic vaccines.

\section{CANDIDATE VACCINES BASED ON RECOMBINANT BACTERIA}

Candidate recombinant bacterial HR HPV vaccines are based, in particular, on Lactobacillus lactis, Lactobacillus plantarum, Lactobacillus casei, Lactobacillus lactis, and Listeria monocytogenes. The safety and efficacy of oral vaccination with the live bacterial vector therapeutic vaccine GLBL101c based on the recombinant $L$. casei strain expressing modified E7 protein of HPV 16 have been tested in clinical trials in 17 patients with HPV 16-associated cervical intraepithelial neoplasia (CIN) [43]. Patients who received 4-6 doses of the vaccine per day showed a significant increase in the E7-specific cellular immune response in the cervix and vagina. After nine weeks, the majority of patients in this group (69\%) showed a decrease in the pathology severity; within a year, regression to low grade squamous intraepithelial lesions (LSIL) was observed in 56\% patients [43]. No effect was observed in patients treated with 1-2 doses, which demonstrated that induction of E7-specific IFN $\gamma$-producing cells depends on the immunogen dose with saturation at $0.3 \mu \mathrm{g}$ E7 per $10^{8}$ cells. To optimize the vaccine efficacy, it was necessary to increase the level of E7 expression by L. casei cells. This was achieved in the new live bacterial vector therapeutic vaccine IGMKK16E7. Immunization with IGMKK16E7 resulted in a 4-fold increase in the induction of E7-specific IFN $\gamma$-producing mucosal cells as compared to GLBL101c [44], which is expected to contribute to a more pronounced therapeutic effect in future. 
The main approaches used in the development of therapeutic vaccines and the basic mechanisms used to induce antigen-specific T-cell immune response

\begin{tabular}{|c|c|c|c|}
\hline Vaccine type & Advantages & Limitations & $\begin{array}{l}\text { Examples } \\
\text { of clinical use }\end{array}$ \\
\hline 1 & 2 & 3 & 4 \\
\hline $\begin{array}{l}\text { Live bacterial } \\
\text { vectors }\end{array}$ & $\begin{array}{l}\text { high immunogenicity; } \\
\text { large selection of available vectors; } \\
\text { APCs can deliver both expressed } \\
\text { protein and genetically engineered } \\
\text { plasmid }\end{array}$ & $\begin{array}{l}\text { potential toxicity/danger, especially } \\
\text { for immunosuppressed patients; } \\
\text { possible pre-existing immunity; } \\
\text { generation of neutralizing antibodies } \\
\text { limiting the effectiveness of re-intro- } \\
\text { duction }\end{array}$ & $\begin{array}{l}\text { GLBL101c. Other names: BLS- } \\
\text { ILB-E710c, CIN therapeutic vac- } \\
\text { cine, AnGes (AnGes/Bioleaders/ } \\
\text { GenoLac/Morishita Jintan/ } \\
\text { University of Tokyo, Japan); } \\
\text { Lovaxin C: attenuated L. monocyto- } \\
\text { genes expressing E7 HPV } 16 \\
\text { (Advaxis, NJ, USA) }\end{array}$ \\
\hline Viral vectors & $\begin{array}{l}\text { high immunogenicity; } \\
\text { large selection of available vectors; } \\
\text { different immunological features } \\
\text { of different vectors and possibility } \\
\text { of their combinations during het- } \\
\text { erologous immunization; } \\
\text { ability to create structures that } \\
\text { define expression of factors stimu- } \\
\text { lating and directing the immune } \\
\text { response (cytokines, molecular } \\
\text { adjuvants) }\end{array}$ & $\begin{array}{l}\text { potential toxicity/danger, especially } \\
\text { for immunosuppressed patients; } \\
\text { possible pre-existing immunity; } \\
\text { generation of neutralizing antibodies, } \\
\text { limiting the effectiveness of re-intro- } \\
\text { duction; } \\
\text { dominance of immune response to } \\
\text { the viral vector proteins over immune } \\
\text { response to immunogens encoded in } \\
\text { the vector sequence }\end{array}$ & $\begin{array}{l}\text { MVA E2/E7 (Transgene, France); } \\
\text { MVA E2 (Lemery, Mexico) }\end{array}$ \\
\hline $\begin{array}{l}\text { RNA repli- } \\
\text { cons* }\end{array}$ & $\begin{array}{l}\text { ability to amplify in transfected } \\
\text { cells; } \\
\text { non-infectious, without the risk of } \\
\text { chromosomal integration and/or } \\
\text { cell transformation; } \\
\text { large selection of available vectors }\end{array}$ & $\begin{array}{l}\text { low stability, difficulties with storage } \\
\text { and usage; } \\
\text { initiation of apoptosis in transfected } \\
\text { cells, reducing immunogenicity; } \\
\text { difficulties in preparation, produc- } \\
\text { tion, and scaling-up }\end{array}$ & $\begin{array}{l}\text { Vvax001, Semliki Forest virus, } \\
\text { expressing E6/E7 HPV } 16 \\
\text { (ViciniVax B.V, Netherlands) }\end{array}$ \\
\hline $\begin{array}{l}\text { Synthetic } \\
\text { peptides }\end{array}$ & $\begin{array}{l}\text { stability, safety, ease of production; } \\
\text { capacity to include a wide range of } \\
\text { epitopes; } \\
\text { possibility of modification to } \\
\text { improve binding to MHC }\end{array}$ & $\begin{array}{l}\text { mandatory prior mapping of epitopes } \\
\text { as a part of potential immunogen } \\
\text { selection; } \\
\text { low immunogenicity; } \\
\text { HLA restriction }\end{array}$ & $\begin{array}{l}\text { PepCan, peptides from HPV 16 E6; } \\
\text { NCT02481414*** (University of } \\
\text { Arkansas, USA); } \\
\text { ISA101/ISA101b (HPV16-SLP), } 13 \\
\text { SLP, overlapping HPV 16 E6 and } \\
\text { E7, NCT02128126*** (ISA } \\
\text { Pharmaceuticals); } \\
\text { HPV 16 E7 peptides (Peninsula } \\
\text { Labs Inc, CA, USA); } \\
\text { E6/E7 peptides (University Medical } \\
\text { Center, Leiden, Netherlands) }\end{array}$ \\
\hline $\begin{array}{l}\text { Recombinant } \\
\text { proteins }\end{array}$ & $\begin{array}{l}\text { stability, safety, ease of production; } \\
\text { no MHC class I restriction }\end{array}$ & $\begin{array}{l}\text { low immunogenicity; } \\
\text { predominant induction of the } \\
\text { humoral, rather than cellular } \\
\text { immune response; } \\
\text { difficulties in the isolation and purifi- } \\
\text { cation; } \\
\text { strict requirements for compliance } \\
\text { with the conditions of storage and } \\
\text { transportation through the cold } \\
\text { chain }\end{array}$ & $\begin{array}{l}\text { ADXS11-001: HPV } 16 \text { E7 fused to } \\
\text { Listeria LOO protein (Advaxis, Inc., } \\
\text { USA); } \\
\text { chimera PD-E7 HPV } 16 \text { (GSK } \\
\text { Biologicals, Belgium); } \\
\text { chimera E6/E7 HPV } 16 \text { (Iscotec } \\
\text { AB, Sweden); } \\
\text { chimera E7 HPV } 16 \text { and heat shock } \\
\text { protein (Nventa, California, USA) }\end{array}$ \\
\hline
\end{tabular}


Table (Contd.)

\begin{tabular}{|c|c|c|c|}
\hline 1 & 2 & 3 & 4 \\
\hline $\begin{array}{l}\text { DNA vac- } \\
\text { cines }\end{array}$ & $\begin{array}{l}\text { stability, safety, ease of production, } \\
\text { storage and transportation; } \\
\text { long-term expression of the } \\
\text { encoded protein, supporting induc- } \\
\text { tion of stronger immune response; } \\
\text { lack of immune response to the } \\
\text { vector, providing the possibility of } \\
\text { repeated injections; } \\
\text { possibility of constructing DNA } \\
\text { for immunogens with the inclu- } \\
\text { sion of both target vaccine and } \\
\text { auxiliary coding sequences (adju- } \\
\text { vants, cytokines, growth factors, } \\
\text { etc.); } \\
\text { a variety of delivery methods }\end{array}$ & $\begin{array}{l}\text { relatively low immunogenicity; } \\
\text { lack of ability to amplify and spread } \\
\text { to surrounding cells, which limits the } \\
\text { expression level; } \\
\text { potential risk of integration into the } \\
\text { chromosome, although its frequency } \\
\text { does not exceed the frequency of } \\
\text { spontaneous integration of } E \text {. coli } \\
\text { DNA; } \\
\text { potential risk of autoimmune } \\
\text { response induction, although it has } \\
\text { been shown that the risk is minimal } \\
\text { and does not depend on the plasmid } \\
\text { introduction, but on the properties of } \\
\text { the encoded protein }\end{array}$ & $\begin{array}{l}\text { ZYC101a: E6/E7 of HPV } 16 \text { and } 18 \\
\text { (MGI Pharma, USA); } \\
\text { VGX-3100: HPV-16 and HPV-18 } \\
\text { E6/E7 (Inovio Pharmaceuticals, } \\
\text { USA); } \\
\text { pNGVL4a-CRT/E7(Detox): HPV- } \\
\text { 16 E7 (NCI RAID, USA); } \\
\text { pNGVL4a-Sig/E7(Detox)/Hsp70: } \\
\text { E7 HPV 16 (NCI, USA); } \\
\text { GX-188E: E6/E7 HPV 16 and } 18 \\
\text { (Genexine Inc., Korea); } \\
\text { VB10: HPV-16 E6/E7 (Vaccibody } \\
\text { AS, Norway) }\end{array}$ \\
\hline $\begin{array}{l}\text { Antigen-pre- } \\
\text { senting, in } \\
\text { particular, } \\
\text { dendritic cells }\end{array}$ & $\begin{array}{l}\text { highly immunogenic; } \\
\text { natural adjuvant; } \\
\text { many ways of antigen loading }\end{array}$ & $\begin{array}{l}\text { inability to apply to more than one } \\
\text { patient; } \\
\text { highly labor-intensive; } \\
\text { high cost; } \\
\text { lack of quality control and its criteria }\end{array}$ & $\begin{array}{l}\text { autologous DCs loaded with HPV } \\
16 \text { and } 18 \text { E7 (grants NIH R21 } \\
\text { CA094507, Italian Institute of } \\
\text { Health); } \\
\text { BVAC-C, B cells and patient mono- } \\
\text { cytes loaded with HPV } 16 \text { and } 18 \text { E6 } \\
\text { and E7 by adenovirus infection } \\
\text { (Cellid Co., Ltd), NCT02866006 *** }\end{array}$ \\
\hline $\begin{array}{l}\text { Allogeneic } \\
\text { tumor cells }\end{array}$ & $\begin{array}{l}\text { ability to present undefined } \\
\text { tumor-associated antigens }\end{array}$ & $\begin{array}{l}\text { safety considerations concerning the } \\
\text { introduction of tumor cells (even } \\
\text { inactivated) to a patient; } \\
\text { requires autologous tumor cells or an } \\
\text { accessible culture of tumor cells cor- } \\
\text { responding to the patient's tumor; } \\
\text { inapplicability in pre-cancerous con- } \\
\text { ditions, when autologous tumor cells } \\
\text { are still absent; } \\
\text { complexity; } \\
\text { weak antigen presentation }\end{array}$ & $\begin{array}{l}\text { MVX-ONCO-1, NCT02999646*** } \\
\text { (Swiss Group for Clinical Cancer } \\
\text { Research, SAKK, Switzerland); } \\
\text { AlloVax (TM), NCT01998542 } \\
\text { (Immunovative Therapies, Ltd, } \\
\text { Israel) }\end{array}$ \\
\hline
\end{tabular}

* Disadvantages do not apply to combined DNA-RNA replicons.

** Most of these and/or similar vaccines are described in this review.

*** Non-clinical research (ClinicalTrials.gov).

As a bacterial vector, Listeria is of particular interest. Listeria is able to infect macrophages and replicate in the cytoplasm of host cells, avoiding lysis in phagosomes due to the synthesis of the listeriolysin $\mathrm{O}$ toxin (LLO). These properties allow Listeria to localize both to the cytoplasm and endosomal compartments, and therefore, deliver peptide antigens to the cytotoxic $\mathrm{T}$ cells in a complex with MHC class I and to helper T cells in a complex with MHC class II molecules [45]. Already in the preclinical studies, it was shown that LLO reduces the population of regulatory $\mathrm{T}$ cells and promotes an increase in the populations of $\mathrm{CD}^{+} \mathrm{FoxP}^{-}$and $\mathrm{CD} 8^{+} \mathrm{T}$ cells in mice with tumors, thus enhancing the therapeutic and anti-tumor effects of the vaccine against TC-1 tumor cells expressing
E6/E7 [46]. A therapeutic vaccine Lm-LLo-E7 (also known as ADXs11-001, ADXS-HPV and AXAL) was created based on the L. monocytogenes ( $\mathrm{Lm}$ ) strain with defective gene for the key pathogenesis regulator prfA. Listeria were made to secrete HPV 16 E7 chimeric antigen fused to the LLO non-hemolytic fragment [47]. The safety of this vaccine was confirmed in a phase I trial in 15 patients with metastatic, refractory, or recurrent advanced squamous cell carcinoma of the cervix, for whom chemotherapy, radiation therapy, and/or surgery have failed. In three patients, vaccination caused an increase in the proportion of E7-specific IFN $\gamma^{+} \mathrm{T}$ cells among peripheral blood mononuclear cells. In four patients $(30.8 \%)$, a reduction in the total tumor volume 
was observed, which confirmed the therapeutic effect of the vaccine [47]. The efficacy of Lm-LLo-E7 can be assessed more specifically after the completion of a series of clinical trials against HPV-associated anal cancer and squamous cell carcinoma of head and neck (SCCHN) [48].

\section{CANDIDATE VACCINES BASED ON RECOMBINANT VIRUSES AND RNA REPLICONS}

Viral vectors can efficiently infect cells, resulting in the expression of antigens encoded in the virus genome, which triggers an immune response that mimics the response developing in the course of abortive/transient viral infection. This makes viral vectors particularly attractive for the development of therapeutic vaccines against HPV. Several viral vectors, including adenoviruses, adeno-associated viruses, alpha viruses, and vaccinia virus, have been tested for the delivery of HR HPV E6 and E7 antigens.

Viral vaccines based on modified vaccinia virus (Ankara vaccine strain, MVA) have been proven to be particularly efficient. In phase I/II trials, recombinant MVA expressing HPV 16 E6, HPV 16 E7, HPV 18 E6, or HPV 18 E7 induced HPV-specific CTL response in 28\% patients with advanced I/II grade CC [49]. In phase II clinical trials, this vaccine provided $>40 \%$ regression of lesions in $80 \%$ patients aged $42-54$ years with severe vaginal or uterine intraepithelial neoplasia [41]. Another MVA recombinant vector, TG4001, created using the sequences of E6/E7 of HPV 16 and interleukin 2 (IL-2) caused a clinical response in 10 out of 21 patients after six months of treatment. After 12 months, there was a regression of high grade squamous intraepithelial lesions (HSILs) in seven out of 10 patients, and the absence of recurrent neoplastic changes and reinfection of HPV 16 in seven out of eight patients [50].

MVA vectors were also made with HPV antigens other than E6 and E7. The MVA E2 vaccine based on HPV 16 E2 was recently tested in a phase III clinical trial involving 1356 male and female patients. The vaccine demonstrated $>90 \%$ efficacy in the treatment of HPVinduced anogenital intraepithelial lesions [51]. In all male patients the development of HPV-specific cytotoxic $\mathrm{T}$-cell response was observed, leading to the complete eradication of the lesions. E2 is an inhibitor of E6 and E7 expression [18]; introduction of E2 as a component of genetic, in this case, recombinant viral vaccine, can suppress the activity of E6 and E7 in infected cells, reducing their oncogenicity and survival of malignant cells.

A number of candidate therapeutic HPV have been developed based on adenoviral vectors, in which the latter were used to carry the genetic material and to expose immunogens on the viral capsid surface. Such vaccines have been widely used in clinical trials to induce immune response against HIV-1, human hepatitis $\mathrm{C}$ virus, Ebola virus, and malaria [52], but for HPV, they have been studied only in preclinical experiments [6]. Vaccination with the replication-defective adenovirus encoding the CRT protein fused with E7 (CRT/E7) resulted in the successful eradication of E7-expressing tumors in mice, which proves the prospects of such vaccines in clinical practice [53].

Therapeutic HPV vaccines based on the replicons of RNA viruses, including Sindbis virus, Venezuelan Equine Encephalitis virus, and Semliki Forest virus (SFV), have been under development for many years. The ability of these vectors for self-replication ensures stable antigen expression and high immunogenicity. Since viral structural genes are removed from the replicon, no formation of viral particles and induction of neutralizing antibodies occur, which allows re-vaccination. The benefits of RNA replicons include also reduced risks of chromosomal integration and cell transformation.

Vaccines based on recombinant SFV vectors encoding E6 and E7 proteins under the control of translation enhancer (SFV-enhE6,7) were among the first designed vaccines. In mice, a single injection of a low dose of SFVenhE6.7 resulted in a significant reduction of $1500-\mathrm{mm}^{3}$ tumors and complete disappearance of tumors less than $500 \mathrm{~mm}^{3}$ in volume [54]. Intradermal administration of SFV-enhE6,7 by tattoo injection turned out to be the most effective; although the level of antigen synthesis was an order of magnitude lower than after intramuscular administration, immunized mice developed a powerful cytotoxic response against E6 and E7 [55].

Genetic engineering has expanded the range of applications of alphaviral vectors for the delivery and expression of plasmid DNA. Immunization with alphaviral DNA vectors has been shown to cause tumor regression and protection against infection by tumor cells in a number of preclinical models [56]. The presence of genes responsible for the efficient RNA replication provides a high level of transgene expression compared to the expression from plasmid DNA [56]. The first variants of combined DNA/RNA replicon vaccines were called "suicidal DNA" because of apoptosis initiation by the RNA replicon. The therapeutic HPV vaccine developed on this basis has been successfully tested in preclinical models, showing induction of the $\mathrm{CD} 8^{+} \mathrm{T}$-cell response to HPV antigens and antitumor effect in mice [57]. However, the immunogenicity of the candidate vaccine was considered insufficient due to massive apoptosis of transfected cells. To improve the immunogenicity, the gene encoding the anti-apoptotic BCL-xL protein was included in the vector, which increased the survival of transfected APCs and improved the antigen-specific $\mathrm{CD} 8^{+} \mathrm{T}$-cell immune response, as well as promoted the antitumor effect compared to the "suicidal" DNA vector encoding the E7 antigen only [58]. 
Combined DNA/RNA replicon vaccines have been developed further and currently show high efficacy in preventing deaths associated with viral infection and implantation of cancer cells [56], in particular, in preclinical treatments of HPV 16-associated CC in mice [59]. A recent study evaluated antitumor effect of the DNA/RNA replicon constructs encoding E6 and E7 proteins (DREP6,7 ), as well as a variant encoding the reshuffled version of E7 (DREP-E7sh). The purpose of reshuffling was to minimize the potential carcinogenic effect of E7 vaccine preparation retained after the deletion of its motif involved in binding of $\mathrm{pRb}$ with its subsequent targeting to proteasomal degradation. Interestingly, DREP-E7sh delayed tumor growth to a lesser extent than the non-reshuffled version of DREP-E6,7. Incorporation into the recombinant vaccine vector of an auxiliary cassette containing a set of epitopes of T-helper cells, the signal peptide, and the KDEL motif for the import and retention of the encoded proteins in the endoplasmic reticulum (DREPsHelpE6,7; DREP-sHelpE7sh) did not promote the antitumor effect, although accelerated its manifestations [59]. Indirectly, this result indicates the absence of direct need for extensive modification of the viral proteins encoded by the genetic vaccine, except for the removal or modification of the protein domains causing direct adverse effects.

The Kunjin flavivirus (KUN) replicon was recently proposed as an alternative to the alphaviral vectors. The KUN replicon, unlike alphaviral replicons, does not induce apoptosis and ensures direct presentation of the antigen by the transfected dendritic cells (DCs) [60]. KUN replicon carrying coding sequence for the HPV E7 antigens encoded in the plasmid DNA have demonstrated the capacity to induce E7-specific T-cell response and pronounced antitumor effect in preclinical models [61].

On the overall, despite the promising results shown by such vaccines in the preclinical studies and clinical trials against other forms of cancer [62], replicon vaccines against HPV and HPV-associated diseases have not reached the clinical trial stage, except for the recombinant SFV expressing HPV 16 E6/E7 described above (https://clinicaltrials.gov/ct2/show/NCT03141463) (Vvax001; ViciniVax BV, The Netherlands; table). Application of this type of vaccines is in part limited by preexisting immunity against the bacterial/viral antigens of the vector. In addition, the efficacy of vaccines based on viral vectors is reduced because of the induction during vaccination of the antiviral immune response. It is manifested by the development of neutralizing antibodies which limit the effectiveness of the repeated injections of vaccine preparations (with the exception of RNA replicons). Another problem associated with the use of live vector vaccines is the pathogenic potential of the viral and bacterial vectors, which poses certain risks to vaccine safety in immunocompromised patients. These problems have stimulated development of other forms of therapeutic vaccines.

\section{CANDIDATE VACCINES BASED ON SYNTHETIC PEPTIDES}

Peptides representing HPV antigens need no (or very little) processing and are presented by class I and II MHC directly upon their entry into APCs, which ensures efficient stimulation of the $\mathrm{CD} 8^{+}$and $\mathrm{CD} 4^{+} \mathrm{T}$-cell immune response. Characteristic features of the peptide vaccines are the overall stability, safety, and ease of production (table).

Among the first peptide vaccines tested was the PepCan vaccine, consisting of four synthetic peptides corresponding to the sequences of HPV 16 E6 epitopes reinforced with the Candin adjuvant [63]. The PepCan vaccine passed phase I clinical trials in six patients with a stepwise increase of the peptide dose from 50 to $500 \mu \mathrm{g}$. The $50 \mu \mathrm{g}$ dose had the best clinical effect in terms of the capacity to induce the regression of neoplasia. Therapeutic vaccination with this peptide dose was carried in additional 10 patients. Regression of neoplasia was achieved in 50\% vaccinated patients; in three cases, HPV 16 became undetectable; and in nine cases, there was a decrease in the viral load [63]. Currently, this vaccine is in phase II clinical trials (table).

Among other vaccines tested in HLA-A*02+ typed patients with HPV-associated incurable head and neck, anal, and cervical cancers were: Hespecta composed of peptides corresponding to amino acids 71-95 and 127158 of the HPV 16 E6 protein in combination with the Amplivant adjuvant (synthetic ligand of Toll-like receptor 2) (NCT02821494); DPX-E7, a synthetic peptide corresponding to amino acids 11-19 of HPV 16 E7 protein, in combination with cyclophosphamide (NCT02865135); and a number of other vaccine preparations [64] (table). The results of these clinical trials are not yet published.

The utility of therapeutic HPV vaccines is ensured by their immunogenicity and ability to present HPV epitopes to the immune system of the widest possible range of patients. Both qualities are difficult to achieve using short synthetic peptides. To improve the performance of peptide immunogens, they have been covalently linked to lipids and adjuvants, such as chemokines, cytokines, and TLR ligands [65]. These modifications enhance the ability of the prototype vaccines to activate innate and adaptive immunity, in particular, $\mathrm{CD} 8^{+} \mathrm{T}$-cell immune response [12] and allow to overcome the limitations of low immunogenicity, but not of the limited MHC specificity. To ensure the effectiveness of peptide vaccines for each patient, one should identify and include specific epitopes of HPV antigens recognized by the immune system of individual patients [66]. Selection of such epitopes, i.e., vaccine "personification", complicates and lengthens the development of vaccine preparation reducing the chances to timely use it in a patient who already has HPV-associated neoplasia or malignancy. Because of these limitations, vaccines based on short peptides and 
their combinations are considered unsuitable for the large-scale therapy of tumors [64, 67].

An alternative approach was the use peptide vaccines composed of long, synthetic peptides (synthetic long peptides, SLPs), including overlapping ones. Such immunogens were found to induce the antigen-specific T-cell response in several preclinical models $[65,66]$ followed by a series of clinical trials. One of the first to be tested was a peptide vaccine composed of SLPs based on the sequences of E6 and E7 oncoproteins of HPV 16 (HPV16-SLP) [68]. This vaccine includes 25-35 amino acid long peptides, nine from E6 and four from E7 proteins, representing their CTL and T-helper epitopes with an overlap of 10-14 residues [68]. SLP vaccine is combined with the Montanide ISA-51 adjuvant [68]. Double-blind, placebo-controlled phase II studies showed that the HPV16-SLP vaccine induces a longterm immunological memory in patients with low-grade squamous intraepithelial lesions (LSILs), lasting for at least a year and, in some cases, leading to the regression of neoplasias [69]. The clinical response was shown in $79 \%$ of the vaccinated patients; $45 \%$ showed complete regression of neoplastic lesions within 12 months after vaccination. However, the antiviral activity of this vaccine, i.e., its ability to eliminate the virus or at least reduce its load, was not demonstrated. The vaccine was recently tested in the phase I/II trials for the treatment of relapsing CC (https://clinicaltrials.gov/ct2/show/ NCT02128126). Trial results are not yet published, but according to the preliminary data, the immune response against SLPs correlated with an increase in the life expectancy of patients with advanced CC, especially when combined with chemotherapy [70]. In the phase II clinical trial of the candidate SLP-based vaccine preparation ISA $101,56 \%$ of 16 patients showed HPV-induced proliferation of $\mathrm{T}$ cells following vaccination. The ability to develop a strong immune response to SLP correlated with the lifespan of $\mathrm{CC}$ patients after vaccination. The combination of the SLP ISA 101 vaccine with ICIs, in particular, with the antibody against programmed cell death protein 1 (nivolumab), showed an anti-tumor and anti-papillomavirus activity even in patients with incurable HPV-associated cancer (NCT02426892 [71]), while treatment with this antibody without vaccination demonstrated therapeutic effect only in a small number of patients. The clinical response was observed in 33\% of patients treated with SLP ISA 101; their survival rate was 17.5 months, exceeding the survival rate of patients receiving nivolumab alone [71]. Currently, ISA 101 is in phase II clinical trials against HPV-associated SCCHN; phase III trials are scheduled (ISA Pharmaceuticals; https://adisinsight.springer.com/drugs/800027982). In general, therapeutic peptide vaccines have proven to be effective against HPV-associated neoplasias, but their efficacy against HPV-associated cancer is still not high enough.

\section{CANDIDATE VACCINES BASED ON RECOMBINANT PROTEINS}

Like peptide vaccines, protein vaccines are safe and easy to manufacture. The advantage of protein vaccines is that they contain epitopes available to all (or almost all) known HLA types, which allows to bypass the restrictions of HLA types inherent to peptide vaccines $[65,66]$. The disadvantage of protein vaccines is the exogenous nature of the immunogen - proteins are predominantly processed by lysosomes and presented by class II MHC molecules, which results in the induction of strong antibody response, but limited response of the cytotoxic T-lymphocytes [66].

One of the solutions to this limitation is introduction into vaccine formulations of adjuvants and immunostimulating molecules. An example of this approach is creation of the subunit vaccine TA-CIN composed of the L2, E6, and E7 proteins of HPV 16. This vaccine has passed phase I and II clinical trials [72, 73]. The potential of TA-CIN vaccine in the treatment of patients with intraepithelial grade 2 or 3 vaginal neoplasias was enhanced by the local administration of the immunomodulator imiquimod; the effect was tested in a separate phase II trial [74]. The patients received three monthly injections of $128 \mu \mathrm{g}$ of vaccine into the deltoid muscle combined with the topical application of a cream containing 5\% imiquimod. In the absence of side effects, a significant increase in the proportion of infiltrating $\mathrm{CD} 8^{+}$and $\mathrm{CD}^{+} \mathrm{T}$ cells was observed. In $63 \%$ patients, complete regression of lesions was recorded 52 weeks after the start of treatment; the regression correlated with the ability of the vaccine to induce a specific immune response [74, 75].

Another solution is fusion of the protein immunogen to the adjuvants which induce a strong CTL response and provide protection against tumor cell challenge. This approach was implemented in the TVGV-1 vaccine (TheVax Genetics Vaccine Co.), currently in phase IIa clinical trials in patients with HSIL (NCT02576561) [6]. Same approach was used to design therapeutic protein vaccine against HPV 16 and 18 based on the recombinant E6 and E7 proteins which were fused to the catalytically inactive toxin of Bordetella pertussis CyaA (GTL001) [76]. The tolerability and immunogenicity of GTL001 were investigated in the phase I clinical trial in women $(n=47)$ infected with HPV 16 or HPV 18 without neoplastic changes (EudraCT No. 2010-018629-21) [76]. A statistically significant decrease in the viral load was observed in the group receiving $600 \mu \mathrm{g}$ of the GTL001 protein preparation reinforced with imiquimod. This group demonstrated early sustained clearance of HPV 16 and HPV 18. Interestingly, imiquimod increased the strength, but not the frequency of the antigen-specific $\mathrm{T}$-cell immune response. The preparation proved to be safe and immunogenic and was recommended for further clinical trials [76]. 
Immunogenic components of protein vaccines can also be modified by fusion with proteasome-targeting signals, the latter increased presentation of the immunogen via the MHC class I pathway and promotes the induction of the $\mathrm{CD} 8^{+} \mathrm{T}$-cell response [6]. There is also an alternative elegant approach that involves converting the protein immunogen from exogenous to endogenous. Granadillo et al. have developed a hybrid protein vaccine consisting of the HPV 16 E7 protein and a peptide derived from the anti-lipopolysaccharide factor LALF31-52 of Limulus polyphemus [77]. LALF31-52 is a small hydrophobic peptide with immunomodulating properties which directs transport of the carrier protein through the cell membranes. The fusion of LALF31-52 with E7 (LALF-E7) increased the immunogenicity of E7 by improving its presentation. Mice vaccinated with LALF-E7 were protected from tumor growth after xenografting of syngeneic TC-1 tumor cells expressing E7 [77]. Mice with TC-1 tumors vaccinated with LALF-E7 demonstrated E7-specific cellular immune response and regression of tumors. Protection against tumor formation was significantly higher than in control mice vaccinated with E7 or LALF alone. These results confirmed the potentiating effect of the cell-penetrating peptide and showed the potential of such approach for enhancing cellular immunogenicity of protein vaccines. Likewise, therapeutic effect was demonstrated for combinations of protein vaccines with other vaccine forms (heterologous vaccination). Special interest in this regard represent the results of the phase II clinical trial of heterologous vaccination using TA-CIN and the recombinant vaccinia virus expressing HPV 16 proteins (TA-HPV) in patients with anogenital cancer and CIN. The trials assessed several vaccination strategies involving TA-CIN priming followed by TA-HPV boosting and TA-HPV priming followed by TA-CIN boosting. Interestingly, none of these schemes offered advantages over the homologous immunization with recombinant TA-HPV [75]. On the overall, the results of the tests of therapeutic protein HPV vaccines indicate their relatively low efficacy compared to other vaccine forms.

\section{CANDIDATE VACCINES \\ BASED ON PLASMID DNA (DNA VACCINES)}

DNA vaccines are safe, stable, relatively simple and inexpensive to manufacture and have the ability to maintain antigen expression in the cells for a prolonged time, which makes DNA vaccination an attractive and potentially efficient approach for immunotherapy of HPV infection. DNA vaccination involves injection of plasmid DNA encoding HPV E6 and E7 oncoproteins, resulting in in vivo transfection of the recipient cells, after which they synthesize the vaccine antigen which in its turn induces a specific immune response. The use of DNA vaccines does not lead to the formation of neutralizing antibodies to the plasmid vector, which favorably distinguishes DNA vaccines from the live vector vaccines and allows repeated vaccinations [12]. Experts note the ability of the current second-generation DNA vaccines to elicit strong cellular and humoral immune responses [78]. In addition, the use of plasmid DNA simplifies manipulations with the encoded material, including deletion of unwanted, potentially dangerous domains, replacement of peptide fragments and individual amino acids, translocation of protein domains to abolish their biological activity while maintaining the amino acid composition, as well as redirection to alternative pathways of intracellular processing, secretion, and introduction of signals that ensure binding and penetration of vaccines into certain types of cells (e.g., DCs). In case of HR HPV, this implies modification of the E6 and E7 oncoproteins to (i) exclude the induction of genetic instability, immortalization, and transformation of expressing cells, and (ii) enhance the immunogenicity of these vaccine antigens. The disadvantage of DNA vaccines is their inability to amplify and spread from the transfected cells to the surrounding cells, as is the case with the live vector vaccines. Several strategies have been developed to overcome this limitation and to increase the potency of DNA vaccines, namely: (i) increasing the number of DCs expressing the target antigen; (ii) enhancing antigen processing and its presentation by DCs; (iii) optimization of the interactions between DCs and T cells [5].

As examples of such modifications, we can mention the incorporation into DNA vaccines of molecular chaperones, in particular, heat shock protein 70 (HSP70). For instance, a DNA vaccine pNGVL4a-sig/E7(detox)/ HSP70 was developed which encoded a mutant HPV 16 E7 conjugated with HSP70 and signal peptide [79]. In a clinical trial, a group of 12 patients was injected with pNGVL4a-sig/E7(detox)/HSP70 intramuscularly twice with a one-month break, and then boosted with the intramuscular injection of TA-HPV (vaccinia vector encoding E7 protein of HPV 16 and HPV 18) [80]. Seven of 12 vaccinated patients (58\%) developed a specific T-cell immune response, targeted mainly against HPV 16 E7. Despite the absence of the antigen-specific CD8 ${ }^{+} \mathrm{T}$-cell response in the peripheral blood, a significant increase was shown in the proportion of antigen-specific $\mathrm{CD} 8^{+}$ $\mathrm{T}$ cells infiltrating the HPV-associated lesions. This study was one of the first to demonstrate that HPV DNA vaccination can induce a local immune response against HPVinduced lesions [80]. The following clinical trial evaluated the safety, efficacy, and immunogenicity of pNGVL4asig/E7(detox) in patients with HPV 16-associated CIN $2 / 3(n=32)$ [81]. DNA vaccine was injected three times with monthly intervals either intradermally, or intramuscularly, or locally into the cervix muscle. Histological regression to a grade $1 \mathrm{CIN}$ or lower occurred in 8 of 27 (30\%) patients who received all three doses. The greatest 
number of intraepithelial infiltrates of $\mathrm{CD} 8^{+} \mathrm{T}$ cells and the strongest systemic $\mathrm{CD} 8^{+} \mathrm{T}$-cell response were found in the cohort with the intramuscular administration of the vaccine into the cervix, which indicated the importance of the induction of local immune response. The development of such response was facilitated by the fusion of the vaccine antigen with ubiquitin and, as in the case of peptide vaccines, by combination of vaccination with ICI therapy [82]. The results of these tests prove potential clinical efficacy of DNA vaccines for HPV-associated malignancies [81].

In the majority of the studies described above, as well as in other clinical and preclinical trials, immunization was performed by intramuscular injections. This method of DNA vaccine administration mostly leads to the transfection of myocytes which, despite high levels of expression of the vaccine antigens, cannot activate a full-fledged immune response, since they cannot present the antigen as do the APCs. In this scenario, the key role in the antigen presentation to naive $\mathrm{CD} 8^{+}$cytotoxic $\mathrm{T}$ cells belongs to DCs. DCs, via phagocytosis, capture the exogenous vaccine antigen released by the transfected myocytes, process it and present it in the context of MHC class I molecules (so-called cross-presentation mechanism). DCs can also be directly transfected by DNA vaccination and directly present the endogenously expressed vaccine antigen to $\mathrm{CD} 8^{+} \mathrm{T}$ cells [83]. Various approaches to DNA immunization have been proposed to enhance the direct antigen presentation by DCs, specifically intradermal injections in which plasmid DNA is introduced into the tissues enriched with APCs, in particular, DCs. Examples of such vaccinations include successful immunization with plasmids encoding HPV oncoproteins carried by nanoparticles by their injection with intradermal microneedles [84] or tattooing [85].

In one of the most successful clinical trials to date, DNA vaccination with a mixture of plasmids expressing consensus E6 and E7 oncoproteins of HPV 16 and HPV 18 (VGX-3100) was performed by intramuscular injection followed by electroporation in patients with CIN 2/3 (ClinicalTrials.gov, number NCT01304524 and EudraCT, number 2012-001334-33) [9]. This trial enrolled the total of 167 patients who received either VGX-3100 $(n=125)$ or placebo $(n=42)$. Of 107 recipients receiving VGX3100, 53 (49.5\%) demonstrated histopathological regression, compared to $30.6 \%$ in the placebo group $(11 / 36$, $p=0.034$ ) [9]. VGX-3100 was the first therapeutic vaccine to demonstrate efficacy against HSIL associated with HPV 16 and 18. Skeptics argued that no differences between the treated and placebo group would have been identified in a larger patient group due to the relatively high frequency of spontaneous recession of neoplasia. Indeed, 32 to $43 \%$ of HSILs can regress spontaneously [86]. However, further histological studies of the vaccinated group confirmed the described clinical effect [87]. Because of this, therapeutic DNA vaccination with VGX-
3100 can already be considered as a non-surgical treatment option for HPV-associated neoplastic changes, which fundamentally changes the treatment prospects for this common disease.

\section{VACCINES BASED ON AUTOLOGOUS DENDRITIC AND TUMOR CELLS}

The use of autologous DCs is another promising strategy for creating therapeutic vaccines against cancer. This technology includes ex vivo introduction of vaccine antigens into DCs by their infection, transfection with DNA or RNA encoding the HPV antigens, or "loading" with antigens in the form of proteins, peptides, or lysates of tumor cells with subsequent reintroduction of DCs into the patients [88]. Loaded DCs also work as natural adjuvants, increasing the efficiency of antigen-specific immunotherapy against cancer [89]. DC vaccine efficacy can be increased by short interfering RNAs (siRNAs) which suppress the expression in DCs of the transforming growth factor beta and IL-10, which otherwise may promote tumor growth and immunosuppression. The use of this approach provides a noticeable increase in the antitumor effect in the murine model of cancer cells expressing E6/E7 of HPV 16 (TC-1 cell line) [90].

Only one vaccine has been described so far that represented autologous DCs loaded with E7 of HPV 16 and 18 [91]. Patients with cervical cancer $(n=10)$ after the radical tumor resection received increasing doses of the autologous DCs pulsed with the recombinant E7 oncoprotein of HPV 16 and HPV 18 as five injections with three-week intervals. All participants demonstrated specific $\mathrm{CD}^{+}$and antibody immune response against E7; $80 \%$ patients also raised the $\mathrm{CD} 8^{+} \mathrm{T}$-cell immune response, although none of these responses showed dependency on the vaccine dose. The clinical effect of the vaccine has not been described. According to the authors, the results indicated the need for phase II clinical trials [91], but the studies were not continued.

The vaccine antigen can be presented not only by DCs, but also by other APCs. In the candidate BVAC-C vaccine, the antigen was presented by the $B$ cells and monocytes loaded with E6 and E7 of HPV 16 and 18 via adenoviral infection [92]. Currently, BVAC-C is being tested for safety, tolerability, and clinical efficacy in patients with progressive refractory $\mathrm{CC}$ with a high degree of metastasis (https://clinicaltrials.gov/ct2/show/ NCT02866006). The results of these clinical trials are expected after August 2020.

APC/DC vaccines have their limitations. The use of autologous DCs for personalized therapy presents certain technical difficulties, due to which this technology does not scale up well and cannot be widely implemented. Differences in the culturing techniques used in the preparation of DCs can lead to changes in the vaccine quality, 
especially in the absence of standard criteria for its evaluation. In addition, development of a strong immune T-cell response requires DC introduction into the lymphoid organs. The optimal route of administration for such vaccines which would ensure their maximum efficacy has not yet been defined, which affects the clinical trials of these preparations, including ones for the HPVassociated malignancies.

The use of autologous tumor cells as vaccines is based on the fact that these cells contain all tumor-specific proteins, which saves time and effort spent on TAA identification and isolation. This approach implies possible induction of autoimmune response. As a rule, vaccination is done with pre-irradiated tumor cells. To enhance immunogenicity, the cells are often genetically modified to express co-stimulatory molecules, TLR ligands, and cytokines. As an example, administration into mice of HPV 16-induced tumors expressing IL-2, IL-12, and/or granulocyte macrophage colony stimulating factor (GM-CSF) facilitated differentiation of the naïve $\mathrm{T}$ cells into specific effector and helper $\mathrm{T}$ cells and stimulated maturation of granulocytes [93, 94].

Tumor cell-based vaccines have been clinically tested in the treatment of melanoma, pancreatic cancer, renal cell carcinoma, and colorectal cancer, but the number of similar clinical trials applied to HPV-associated tumors is grossly limited. So far, only two personalized vaccines against $\mathrm{SCCHN}$ based on allogenic tumor cells, AlloVax ${ }^{\mathrm{TM}}$ and MVX-ONCO-1, have been tested in phase I/II clinical trials [64].

The first vaccine AlloVax ${ }^{\mathrm{TM}}$ is based on the chaperoneenriched tumor lysates [Chaperone Rich Cell Lysate vaccine/(CRCL)] from patients with incurable SCCHN supplemented with AlloSim ${ }^{\mathrm{TM}}$ adjuvant. The cells are preenriched with chaperones using the same principle as in the DC vaccines. Phase I clinical study of AlloVax ${ }^{\mathrm{TM}}$ was completed in 2016, but the results have not been published, and phase II pre-planned for 2016 was not initiated (https://clinicaltrials.gov/ct2/show/NCT02624999).

The second vaccine, MVX-ONCO-1 contains radiation-killed tumor cells of SCCHN patients. Cells are enriched with GM-CSF and injected in a combination with subcutaneously implanted nanoparticles that facilitate their continuous release. At the moment, MVXONCO-1 is in the phase II clinical trials against SCCHN (with possible association with HPV) in patients not responding to other therapies. The results of these tests have not yet been published (https://clinicaltrials.gov/ ct2/show/NCT02999646).

The scarcity of clinical examples and the lack of visible success indicate limited applicability of this approach for the treatment of HPV-associated neoplasias and cancer. The main advantage of this type of vaccine, i.e., no need for the information about TAAs, is not valid, since oncoproteins involved in HPV-associated malignancies are well known. Compared to other vaccine variants, pro- duction of vaccines based on tumor cells is expensive and labor-intensive. Besides, vaccination with tumor cells can potentially cause new forms of cancer in susceptible patients, which prevents clinical trials in patients with mild HPV-associated dysplasias or precancerous epithelial lesions, i.e., prevents immunotherapy for precancerous conditions. Altogether, this reduces the likelihood of tumor cells becoming the basis of immunotherapeutic HPV vaccines.

The main targets for HPV vaccine therapy are HR HPV E6 and E7 oncoproteins constitutively expressed in precancerous and tumor tissues. High degree of their conservation opens up the possibility for creating a universal vaccine, at least against viruses belonging to the same type of HR HPV. Development of a vaccine against several types of HPV seems to be impossible, since crossrecognition appears to be limited to a narrow spectrum of T-cell epitopes.

E6 and E7 oncoproteins can be presented to the immune system as components of various vaccine types. Both E6 and E7 contribute to the immortalization and transformation of infected HPV cells; they are also responsible for the escape of infected cells from the immune response. Direct use of these oncoproteins as components of HPV vaccine is impossible, a substantial modification is required to limit their oncogenic potential and increase immunogenicity. Such modifications are conveniently implemented on the platform of genetic vaccines, such as plasmid DNA, a combination of DNA with RNA replicons, and live viral or bacterial vectors.

An important achievement in vaccine immunotherapy of cancer is the emergence of ICIs (e.g., Keytruda ${ }^{\circledR}$, pembrolizumab). These drugs are recommended for the combined vaccination/immunotherapy for HPV-associated neoplasias and cancer [95]. Given their efficacy, future vaccination against HPV is likely to include various forms of genetic vaccines in combination with ICI therapy.

So far, with all the diversity of immunotherapeutic vaccines tested, none of the vaccines, including combinations with immunomodulators, have been able to provide complete irreversible regression of HPV-associated malignancies. To create a vaccine with such properties, further large-scale comparative studies are needed with long-term monitoring of the virological, cytological, and immune status of the vaccinated individuals.

Funding. This work was supported by the Russian Foundation for Basic Research (grants nos. 17_54_30002 and 17_04_00583).

Conflict of interest. Authors declare no conflict of interest.

Ethics statement. This article does not contain descriptions of any original research in human and animal subjects. 


\section{REFERENCES}

1. Arbyn, M., Xu, L., Simoens, C., and Martin-Hirsch, P. P. L. (2018) Prophylactic vaccination against human papillomaviruses to prevent cervical cancer and its precursors, Cochrane Database Syst. Rev., 5, CD009069, doi: 10.1002/14651858.CD009069.pub3.

2. Prilepskaya, V. N., Zardiashvili, M. D., Khlebkova, Yu. S., and Nekrasova, M. E. (2016) Vaccination against HPVassociated diseases and cervical cancer: theoretical and practical aspects, Med. Sovet, 12, 120-125, doi: 10.21518/ 2079-701X-2016-12-120-125.

3. Cutts, F. T., Franceschi, S., Goldie, S., Castellsague, X., de Sanjose, S., Garnett, G., Edmunds, W. J., Claeys, P., Goldenthal, K. L., Harper, D. M., and Markowitz, L. (2007) Human papillomavirus and HPV vaccines: a review, Bull. World Health Organ., 85, 719-726, doi: 10.2471/ BLT.06.038414.

4. Vonsky, M. S., Shabaeva, M. G., Runov, A. L., Lebedeva, N. N., Palefsky, D., and Isaguliants, M. G. (2019) Carcinogenesis associated with human papillomavirus infection. Mechanisms and potential for immunotherapy, Biochemistry (Moscow), 84, 782-799.

5. Yang, A., Farmer, E., Wu, T. C., and Hung, C. F. (2016) Perspectives for therapeutic HPV vaccine development, J. Biomed. Sci., 23, 75, doi: 10.1186/s12929-016-0293-9.

6. Chabeda, A., Yanez, R., Jr., Lamprecht, R., Meyers, A. E., Rybicki, E. P., and Hitzeroth, I. I. (2017) Therapeutic vaccines for high-risk HPV-associated diseases, Papillomavirus Res., 5, 46-58, doi: 10.1016/j.pvr.2017.12.006.

7. Petrova, G. V., Gretsova, O. P., Shahzadova, A. O., Prostov, M. Yu., Prostov, Yu. I., and Samsonov, Yu. V. (2018) in Malignant Tumors in Russia in 2017. Morbidity and Mortality (Kaprin, A. D., Starinsky, V. V., and Petrova, G. V., eds.) Hertsen Moscow Oncology Research Center, Moscow, pp. 4-130.

8. Alyautdina, O. S., and Darmostukova, M. A. (2018) Modern aspects of human papillomavirus vaccination, Bezopas. Risk Farmakoter., 6, 111-117, doi: 10.30895/ 2312-7821-2018-6-3-111-117.

9. Trimble, C. L., Morrow, M. P., Kraynyak, K. A., Shen, X., Dallas, M., Yan, J., Edwards, L., Parker, R. L., Denny, L., Giffear, M., Brown, A. S., Marcozzi-Pierce, K., Shah, D., Slager, A. M., Sylvester, A. J., Khan, A., Broderick, K. E., Juba, R. J., Herring, T. A., Boyer, J., Lee, J., Sardesai, N. Y., Weiner, D. B., and Bagarazzi, M. L. (2015) Safety, efficacy, and immunogenicity of VGX-3100, a therapeutic synthetic DNA vaccine targeting human papillomavirus 16 and 18 E6 and E7 proteins for cervical intraepithelial neoplasia 2/3: a randomised, double-blind, placebo-controlled phase 2b trial, Lancet, 386, 2078-2088, doi: 10.1016/S01406736(15)00239-1.

10. Wong, K. K., Li, W. A., Mooney, D. J., and Dranoff, G. (2016) Advances in therapeutic cancer vaccines, $A d v$. Immunol., 130, 191-249, doi: 10.1016/bs.ai.2015.12.001.

11. Kash, N., Lee, M. A., Kollipara, R., Downing, C., Guidry, J., and Tyring, S. K. (2015) Safety and efficacy data on vaccines and immunization to human papillomavirus, J. Clin. Med., 4, 614-633, doi: 10.3390/jcm4040614.

12. Ma, B., Maraj, B., Tran, N. P., Knoff, J., Chen, A., Alvarez, R. D., Hung, C. F., and Wu, T. C. (2012) Emerging human papillomavirus vaccines, Expert Opin.
Emerg. Drugs, 17, 469-492, doi: 10.1517/14728214.2012. 744393.

13. Wise-Draper, T. M., and Wells, S. I. (2008) Papillomavirus E6 and E7 proteins and their cellular targets, Front. Biosci., 13, 1003-1017.

14. Vande Pol, S. B., and Klingelhutz, A. J. (2013) Papillomavirus E6 oncoproteins, Virology, 445, 115-137, doi: 10.1016/j.virol.2013.04.026.

15. Miller, J., Dakic, A., Chen, R., Palechor-Ceron, N., Dai, Y., Kallakury, B., Schlegel, R., and Liu, X. (2013) HPV16 E7 protein and hTERT proteins defective for telomere maintenance cooperate to immortalize human keratinocytes, PLoS Pathog., 9, e1003284, doi: 10.1371/journal.ppat.1003284.

16. Edmonds, C., and Vousden, K. H. (1989) A point mutational analysis of human papillomavirus type $16 \mathrm{E} 7$ protein, J. Virol., 63, 2650-2656.

17. Zine El Abidine, A., Tomaic, V., Bel Haj Rhouma, R., Massimi, P., Guizani, I., Boubaker, S., Ennaifer, E., and Banks, L. (2017) A naturally occurring variant of HPV-16 E7 exerts increased transforming activity through acquisition of an additional phospho-acceptor site, Virology, 500, 218-225, doi: 10.1016/j.virol.2016.10.023.

18. Doorbar, J. (2016) Model systems of human papillomavirus-associated disease, J. Pathol., 238, 166-179, doi: 10.1002/path.4656.

19. Song, S., Pitot, H. C., and Lambert, P. F. (1999) The human papillomavirus type $16 \mathrm{E} 6$ gene alone is sufficient to induce carcinomas in transgenic animals, J. Virol., 73, 5887-5893.

20. De Azambuja, K., Barman, P., Toyama, J., David, E. D., Lawson, G. W., Williams, L. K., Chua, K., Lee, D., Kehoe, J. J., Brodkorb, A., Schwiebert, R., Kitchen, S., Bhimani, A., and Wiley, D. J. (2014) Validation of an HPV16-mediated carcinogenesis mouse model, In vivo, 28, 761-767.

21. Iuliano, M., Mangino, G., Chiantore, M. V., Zangrillo, M. S., Accardi, R., Tommasino, M., Fiorucci, G., and Romeo, G. (2018) Human papillomavirus E6 and E7 oncoproteins affect the cell microenvironment by classical secretion and extracellular vesicles delivery of inflammatory mediators, Cytokine, 106, 182-189, doi: 10.1016/j.cyto. 2017.11.003.

22. Mirabello, L., Yeager, M., Yu, K., Clifford, G. M., Xiao, Y., Zhu, B., Cullen, M., Boland, J. F., Wentzensen, N., Nelson, C. W., Raine-Bennett, T., Chen, Z., Bass, S., Song, L., Yang, Q., Steinberg, M., Burdett, L., Dean, M., Roberson, D., Mitchell, J., Lorey, T., Franceschi, S., Castle, P. E., Walker, J., Zuna, R., Kreimer, A. R., Beachler, D. C., Hildesheim, A., Gonzalez, P., Porras, C., Burk, R. D., and Schiffman, M. (2017) HPV16 E7 genetic conservation is critical to carcinogenesis, Cell, 170, 11641174, doi: 10.1016/j.cell.2017.08.001.

23. Zhang, G. L., Riemer, A. B., Keskin, D. B., Chitkushev, L., Reinherz, E. L., and Brusic, V. (2014) HPVdb: a data mining system for knowledge discovery in human papillomavirus with applications in T-cell immunology and vaccinology, Database (Oxford), 2014, bau031, doi: 10.1093/ database/bau031.

24. Chan, P. K., Liu, S. J., Cheung, J. L., Cheung, T. H., Yeo, W., Chong, P., and Man, S. (2011) T-cell response to human papillomavirus type $52 \mathrm{~L} 1, \mathrm{E} 6$, and E7 peptides in women with transient infection, cervical intraepithelial 
neoplasia, and invasive cancer, J. Med. Virol., 83, 10231030, doi: 10.1002/jmv.21889.

25. Nakagawa, M., Kim, K. H., Gillam, T. M., and Moscicki, A. B. (2006) HLA class I binding promiscuity of the CD8 T-cell epitopes of human papillomavirus type 16 E6 protein, J. Virol., 81, 1412-1423, doi: 10.1128/JVI.01768-06.

26. De Vos van Steenwijk, P. J., Heusinkveld, M., Ramwadhdoebe, T. H., Lowik, M. J., van der Hulst, J. M., Goedemans, R., Piersma, S. J., Kenter, G. G., and van der Burg, S. H. (2010) An unexpectedly large polyclonal repertoire of HPV-specific T-cells is poised for action in patients with cervical cancer, Cancer Res., 70, 2707-2717, doi: 10.1158/0008-5472.CAN-09-4299.

27. Grabowska, A. K., Kaufmann, A. M., and Riemer, A. B. (2015) Identification of promiscuous HPV16-derived T helper cell epitopes for therapeutic HPV vaccine design, Int. J. Cancer, 136, 212-224, doi: 10.1002/ijc. 28968.

28. Evans, M., Borysiewicz, L. K., Evans, A. S., Rowe, M., Jones, M., Gileadi, U., Cerundolo, V., and Man, S. (2001) Antigen processing defects in cervical carcinomas limit the presentation of a CTL epitope from human papillomavirus 16 E6, J. Immunol., 167, 5420-5428, doi: 10.4049/jimmunol.167.9.5420.

29. Peng, S., Trimble, C., Wu, L., Pardoll, D., Roden, R., Hung, C. F., and Wu, T. C. (2007) HLA-DQB $1 * 02-$ restricted HPV-16 E7 peptide-specific CD4+ T-cell immune responses correlate with regression of HPV-16associated high-grade squamous intraepithelial lesions, Clin. Cancer Res., 13, 2479-2487, doi: 10.1158/10780432.CCR-06-2916.

30. Van den Hende, M., Redeker, A., Kwappenberg, K. M., Franken, K. L., Drijfhout, J. W., Oostendorp, J., Valentijn, A. R., Fathers, L. M., Welters, M. J., Melief, C. J., Kenter, G. G., van der Burg, S. H., and Offringa, R. (2010) Evaluation of immunological cross-reactivity between clade A9 high-risk human papillomavirus types on the basis of E6-specific $\mathrm{CD}^{+}$memory T-cell responses, J. Infect. Dis., 202, 1200-1211, doi: 10.1086/656367.

31. Kim, K. H., Dishongh, R., Santin, A. D., Cannon, M. J., Bellone, S., and Nakagawa, M. (2006) Recognition of a cervical cancer derived tumor cell line by a human papillomavirus type 16 E6 52-61-specific CD8 T-cell clone, Cancer Immun., 6, 9.

32. Christensen, N. D., Budgeon, L. R., Cladel, N. M., and $\mathrm{Hu}$, J. (2016) Recent advances in preclinical model systems for papillomaviruses, Virus Res., 231, 108-118, doi: 10.1016/j.virusres.2016.12.004.

33. Lin, K. Y., Guarnieri, F. G., Staveley-O'Carroll, K. F., Levitsky, H. I., August, J. T., Pardoll, D. M., and Wu, T. C. (1996) Treatment of established tumors with a novel vaccine that enhances major histocompatibility class II presentation of tumor antigen, Cancer Res., 56, 21-26.

34. Cheng, W. F., Hung, C. F., Lin, K. Y., Ling, M., Juang, J., He, L., Lin, C. T., and Wu, T. C. (2003) CD8+ T-cells, NK cells and IFN-gamma are important for control of tumor with downregulated MHC class I expression by DNA vaccination, Gene Ther., 10, 1311-1320, doi: 10.1038/sj.gt. 3301982

35. Beyranvand, N. E., van der Sluis, T. C., van Duikeren, S., Yagita, H., Janssen, G. M., van Veelen, P. A., Melief, C. J., van der Burg, S. H., and Arens, R. (2016) Tumor eradication by cisplatin is sustained by CD80/86-mediated costim- ulation of CD8 $8^{+}$T-cells, Cancer Res., 76, 6017-6029, doi: 10.1158/0008-5472.CAN-16-0881.

36. Liu, Z., Zhou, H., Wang, W., Fu, Y. X., and Zhu, M. (2016) A novel dendritic cell targeting HPV16 E7 synthetic vaccine in combination with PD-L1 blockade elicits therapeutic antitumor immunity in mice, Oncoimmunology, 5, e1147641, doi: 10.1080/2162402X.2016.1147641.

37. Mkrtichyan, M., Chong, N., Abu, E. R., Wallecha, A., Singh, R., Rothman, J., and Khleif, S. N. (2013) Anti-PD1 antibody significantly increases therapeutic efficacy of Listeria monocytogenes (Lm)-LLO immunotherapy, J. Immunother. Cancer, 1, 15, doi: 10.1186/2051-1426-1-15.

38. Song, L., Yang, M. C., Knoff, J., Wu, T. C., and Hung, C. F. (2014) Cancer immunotherapy employing an innovative strategy to enhance CD4+ T-cell help in the tumor microenvironment, PloS One, 9, e115711, doi: 10.1371/ journal.pone.0115711.

39. Peng, S., Qiu, J., Yang, A., Yang, B., Jeang, J., Wang, J. W., Chang, Y. N., Brayton, C., Roden, R. B., Hung, C. F., and Wu, T. C. (2016) Optimization of heterologous DNAprime, protein boost regimens and site of vaccination to enhance therapeutic immunity against human papillomavirus-associated disease, Cell Biosci., 6, 16, doi: 10.1186/s13578-016-0080-z.

40. Nakagawa, M., Stites, D. P., Patel, S., Farhat, S., Scott, M., Hills, N. K., Palefsky, J. M., and Moscicki, A. B. (2000) Persistence of human papillomavirus type 16 infection is associated with lack of cytotoxic T lymphocyte response to the E6 antigens, J. Infect. Dis., 182, 595-598, doi: 10.1086/315706.

41. Baldwin, P. J., van der Burg, S. H., Boswell, C. M., Offringa, R., Hickling, J. K., Dobson, J., Roberts, J. S., Latimer, J. A., Moseley, R. P., Coleman, N., Stanley, M. A., and Sterling, J. C. (2003) Vaccinia-expressed human papillomavirus 16 and $18 \mathrm{e} 6$ and e7 as a therapeutic vaccination for vulval and vaginal intraepithelial neoplasia, Clin. Cancer Res., 9, 5205-5213.

42. Cordeiro, M. N., De Lima, R. C. P., Paolini, F., Melo, A. R. D. S., Campos, A. P. F., Venuti, A., and De Freitas, A. C. (2018) Current research into novel therapeutic vaccines against cervical cancer, Expert Rev. Anticancer Ther., 18, 365-376, doi: 10.1080/14737140.2018.1445527.

43. Kawana, K., Adachi, K., Kojima, S., Taguchi, A., Tomio, K., Yamashita, A., Nishida, H., Nagasaka, K., Arimoto, T., Yokoyama, T., Wada-Hiraike, O., Oda, K., Sewaki, T., Osuga, Y., and Fujii, T. (2014) Oral vaccination against HPV E7 for treatment of cervical intraepithelial neoplasia grade 3 (CIN3) elicits E7-specific mucosal immunity in the cervix of CIN3 patients, Vaccine, 32, 6233-6239, doi: 10.1016/j.vaccine.2014.09.020.

44. Komatsu, A., Igimi, S., and Kawana, K. (2018) Optimization of human papillomavirus (HPV) type 16 E7-expressing lactobacillus-based vaccine for induction of mucosal E7-specific IFN $\gamma$-producing cells, Vaccine, 36, 3423-3426, doi: 10.1016/j.vaccine.2018.05.009.

45. Peters, C., and Paterson, Y. (2003) Enhancing the immunogenicity of bioengineered Listeria monocytogenes by passaging through live animal hosts, Vaccine, 21, 11871194, doi: 10.1016/S0264-410X(02)00554-6.

46. Chen, Z., Ozbun, L., Chong, N., Wallecha, A., Berzofsky, J. A., and Khleif, S. N. (2014) Episomal expression of truncated listeriolysin $\mathrm{O}$ in LmddA-LLO-E7 vaccine enhances 
antitumor efficacy by preferentially inducing expansions of $\mathrm{CD}^{+}{ }^{+}$FoxP $^{-}$and $\mathrm{CD}^{+}$T-cells, Cancer Immunol. Res., 2 , 911-922, doi: 10.1158/2326-6066.CIR-13-0197.

47. Maciag, P. C., Radulovic, S., and Rothman, J. (2009) The first clinical use of a live-attenuated Listeria monocytogenes vaccine: a phase I safety study of Lm-LLO-E7 in patients with advanced carcinoma of the cervix, Vaccine, 27, 39753983, doi: 10.1016/j.vaccine.2009.04.041.

48. Miles, B. A., Monk, B. J., and Safran, H. P. (2017) Mechanistic insights into ADXS11-001 human papillomavirus-associated cancer immunotherapy, Gynecol. Oncol. Res. Pract., 4, 9, doi: 10.1186/s40661-017-0046-9.

49. Kaufmann, A. M., Stern, P. L., Rankin, E. M., Sommer, H., Nuessler, V., Schneider, A., Adams, M., Onon, T. S., Bauknecht, T., Wagner, U., Kroon, K., Hickling, J., Boswell, C. M., Stacey, S. N., Kitchener, H. C., Gillard, J., Wanders, J., Roberts, J. S., and Zwierzina, H. (2002) Safety and immunogenicity of TA-HPV, a recombinant vaccinia virus expressing modified human papillomavirus (HPV)-16 and HPV-18 E6 and E7 genes, in women with progressive cervical cancer, Clin. Cancer Res., 8, 36763685 .

50. Brun, J. L., Dalstein, V., Leveque, J., Mathevet, P., Raulic, P., Baldauf, J. J., Scholl, S., Huynh, B., Douvier, S., Riethmuller, D., Clavel, C., Birembaut, P., Calenda, V., Baudin, M., and Bory, J. P. (2011) Regression of high-grade cervical intraepithelial neoplasia with TG4001 targeted immunotherapy, Am. J. Obst. Gynecol., 204, e1-e8, doi: 10.1016/j.ajog.2010.09.020.

51. Rosales, R., Lopez-Contreras, M., Rosales, C., Magallanes-Molina, J. R., Gonzalez-Vergara, R., ArroyoCazarez, J. M., Ricardez-Arenas, A., Del Follo-Valencia, A., Padilla-Arriaga, S., Guerrero, M. V., Pirez, M. A., Arellano-Fiore, C., and Villarreal, F. (2014) Regression of human papillomavirus intraepithelial lesions is induced by MVA E2 therapeutic vaccine, Hum. Gene Ther., 25, 10351049, doi: 10.1089/hum.2014.024.

52. Vujadinovic, M., and Vellinga, J. (2018) Progress in adenoviral capsid-display vaccines, Biomedicines, 6, E81, doi: 10.3390/biomedicines6030081.

53. Gomez-Gutierrez, J. G., Elpek, K. G., Montes de OcaLuna, R., Shirwan, H., Sam Zhou, H., and McMasters, K. M. (2007) Vaccination with an adenoviral vector expressing calreticulin-human papillomavirus 16 E7 fusion protein eradicates E7 expressing established tumors in mice, Cancer Immunol. Immunother., 56, 997-1007, doi: 10.1007/ s00262-006-0247-2.

54. Daemen, T., Riezebos-Brilman, A., Regts, J., Dontje, B., van der Zee, A., and Wilschut, J. (2004) Superior therapeutic efficacy of alphavirus-mediated immunization against human papilloma virus type 16 antigens in a murine tumour model: effects of the route of immunization, Antivir. Ther., 9, 733-742.

55. Van de Wall, S., Walczak, M., van Rooij, N., Hoogeboom, B. N., Meijerhof, T., Nijman, H. W., and Daemen, T. (2015) Tattoo delivery of a Semliki Forest Virus-based vaccine encoding human papillomavirus E6 and E7, Vaccines (Basel), 3, 221-238, doi: 10.3390/vaccines3020221.

56. Lundstrom, K. (2019) Plasmid DNA-based alphavirus vaccines, Vaccines, 7, 29, doi: 10.3390/vaccines7010029.

57. Hsu, K. F., Hung, C. F., Cheng, W. F., He, L., Slater, L. A., Ling, M., and Wu, T. C. (2001) Enhancement of suicidal
DNA vaccine potency by linking Mycobacterium tuberculosis heat shock protein 70 to an antigen, Gene Ther., 8, 376383, doi: $10.1038 /$ sj.gt.3301408.

58. Kim, T. W., Hung, C. F., Juang, J., He, L., Hardwick, J. M., and $\mathrm{Wu}, \mathrm{T}$. C. (2004) Enhancement of suicidal DNA vaccine potency by delaying suicidal DNA-induced cell death, Gene Ther., 11, 336-342, doi: 10.1038/sj.gt.3302164.

59. Van de Wall, S., Ljungberg, K., Ip, P. P., Boerma, A., Knudsen, M. L., Nijman, H. W., Liljestrom, P., and Daemen, T. (2018) Potent therapeutic efficacy of an alphavirus replicon DNA vaccine expressing human papilloma virus E6 and E7 antigens, Oncoimmunology, 7, e1487913, doi: 10.1080/2162402X.2018.1487913.

60. Varnavski, A. N., Young, P. R., and Khromykh, A. A. (2000) Stable high-level expression of heterologous genes in vitro and in vivo by noncytopathic DNA-based Kunjin virus replicon vectors, J. Virol., 74, 4394-4403, doi: 10.1128/ JVI.74.9.4394-4403.2000.

61. Herd, K. A., Harvey, T., Khromykh, A. A., and Tindle, R. W. (2004) Recombinant Kunjin virus replicon vaccines induce protective T-cell immunity against human papillomavirus 16 E7-expressing tumour, Virology, 319, 237-248, 10.1016/j.virol.2003.10.032.

62. Sebastian, M., Papachristofilou, A., Weiss, C., Fruh, M., Cathomas, R., Hilbe, W., Wehler, T., Rippin, G., Koch, S. D., Scheel, B., Fotin-Mleczek, M., Heidenreich, R., Kallen, K. J., Gnad-Vogt, U., and Zippelius, A. (2014) Phase Ib study evaluating a self- adjuvanted mRNA cancer vaccine (RNActive ${ }^{\circledR}$ ) combined with local radiation as consolidation and maintenance treatment for patients with stage IV non-small cell lung cancer, BMC Cancer, 14, 748, doi: 10.1186/1471-2407-14-748.

63. Coleman, H. N., Greenfield, W. W., Stratton, S. L., Vaughn, R., Kieber, A., Moerman-Herzog, A. M., Spencer, H. J., Hitt, W. C., Quick, C. M., Hutchins, L. F., Mackintosh, S. G., Edmondson, R. D., Erickson, S. W., and Nakagawa, M. (2016) Human papillomavirus type 16 viral load is decreased following a therapeutic vaccination, Cancer Immunol. Immunother., 65, 563-573, doi: 10.1007/ s00262-016-1821-x.

64. Wang, C., Dickie, O., Sutavani, K. M., Pointer, C., Thomas, G. J., and Savelyeva, N. (2018) Targeting head and neck cancer by vaccination, Front. Immunol., 9, 830, doi: 10.3389/fimmu.2018.00830.

65. Lin, K., Doolan, K., Hung, C. F., and Wu, T. C. (2010) Perspectives for preventive and therapeutic HPV vaccines, J. Formos. Med. Assoc., 109, 4-24, doi: 10.1016/S09296646(10)60017-4.

66. Su, J. H., Wu, A., Scotney, E., Ma, B., Monie, A., Hung, C. F., and $\mathrm{Wu}, \mathrm{T}$. C. (2010) Immunotherapy for cervical cancer: research status and clinical potential, BioDrugs, 24, 109-129, doi: 10.2165/11532810-000000000-00000.

67. Hung, C. F., Ma, B., Monie, A., Tsen, S. W., and Wu, T. C. (2008) Therapeutic human papillomavirus vaccines: current clinical trials and future directions, Expert Opin. Biol. Ther., 8, 421-439, doi: 10.1517/14712598.8.4.421.

68. Zwaveling, S., Ferreira Mota, S. C., Nouta, J., Johnson, M., Lipford, G. B., Offringa, R., van der Burg, S. H., and Melief, C. J. (2002) Established human papillomavirus type 16 -expressing tumors are effectively eradicated following vaccination with long peptides, J. Immunol., 169, 350-358, doi: 10.4049/jimmunol.169.1.350. 
69. De Vos van Steenwijk, P. J., van Poelgeest, M. I., Ramwadhdoebe, T. H., Lowik, M. J., Berends-van der Meer, D. M., van der Minne, C. E., Loof, N. M., Stynenbosch, L. F., Fathers, L. M., Valentijn, A. R., Oostendorp, J., Osse, E. M., Fleuren, G. J., Nooij, L., Kagie, M. J., Hellebrekers, B. W., Melief, C. J., Welters, M. J., van der Burg, S. H., and Kenter, G. G. (2014) The long-term immune response after HPV16 peptide vaccination in women with low-grade premalignant disorders of the uterine cervix: a placebo-controlled phase II study, Cancer Immunol. Immunother., 63, 147-160, doi: 10.1007/s00262-013-1499-2.

70. Melief, C. J., Gerritsen, W. R., Welters, M., Vergote, I., Kroep, J. R., Kenter, G., Ottevanger, P. B., Tjalma, W. A., Denys, H., Nijman, H., van Poelgeest, M. I. E., Reyners, A. K. L., Velu, T. J., Blumenstein, B. A., Goffin, F., Lalisang, R. I., Stead, R. B., and van der Burg, S. (2017) Correlation between strength of $\mathrm{T}$-cell response against HPV16 and survival after vaccination with HPV16 long peptides in combination with chemotherapy for late-stage cervical cancer, J. Clin. Oncol., 35, 140, doi: 10.1200/ JCO.2017.35.7_suppl.140.

71. Massarelli, E., William, W., Johnson, F., Kies, M., Ferrarotto, R., Guo, M., Feng, L., Lee, J. J., Tran, H., Kim, Y. U., Haymaker, C., Bernatchez, C., Curran, M., Zecchini Barrese, T., Rodriguez Canales, J., Wistuba, I., Li, L., Wang, J., van der Burg, S. H., Melief, C. J., and Glisson, B. (2019) Combining immune checkpoint blockade and tumor-specific vaccine for patients with incurable human papillomavirus 16 -related cancer: a phase 2 clinical trial, JAMA Oncol., 5, 67-73, doi: 10.1001/jamaoncol.2018.4051.

72. Van der Burg, S. H., Kwappenberg, K. M., O’Neill, T., Brandt, R. M., Melief, C. J., Hickling, J. K., and Offringa, R. (2001) Pre-clinical safety and efficacy of TA-CIN, a recombinant HPV16 L2E6E7 fusion protein vaccine, in homologous and heterologous prime-boost regimens, Vaccine, 19, 3652-3660.

73. De Jong, A., O’Neill, T., Khan, A. Y., Kwappenberg, K. M., Chisholm, S. E., Whittle, N. R., Dobson, J. A., Jack, L. C., St. Clair Roberts, J. A., Offringa, R., van der Burg, S. H., and Hickling, J. K. (2002) Enhancement of human papillomavirus (HPV) type 16 E6 and E7-specific T-cell immunity in healthy volunteers through vaccination with TA-CIN, an HPV16 L2E7E6 fusion protein vaccine, Vaccine, 20, 3456-3464.

74. Daayana, S., Elkord, E., Winters, U., Pawlita, M., Roden, R., Stern, P. L., and Kitchener, H. C. (2010) Phase II trial of imiquimod and HPV therapeutic vaccination in patients with vulval intraepithelial neoplasia, Br. J. Cancer, 102, 1129-1136, doi: 10.1038/sj.bjc.6605611.

75. Hibbitts, S. (2010) TA-CIN, a vaccine incorporating a recombinant HPV fusion protein (HPV16 L2E6E7) for the potential treatment of HPV16-associated genital diseases, Curr. Opin. Mol. Ther., 12, 598-606.

76. Van Damme, P., Bouillette-Marussig, M., Hens, A., De Coster, I., Depuydt, C., Goubier, A., Van Tendeloo, V., Cools, N., Goossens, H., Hercend, T., Timmerman, B., and Bissery, M. C. (2016) GTL001, a therapeutic vaccine for women infected with human papillomavirus 16 or 18 and normal cervical cytology: results of a phase I clinical trial, Clin. Cancer Res., 22, 3238-3248, doi: 10.1158/10780432.CCR-16-0085.
77. Granadillo, M., Vallespi, M. G., Batte, A., Mendoza, O., Soria, Y., Lugo, V. M., and Torrens, I. (2011) A novel fusion protein-based vaccine comprising a cell penetrating and immunostimulatory peptide linked to human papillomavirus (HPV) type $16 \mathrm{E} 7$ antigen generates potent immunologic and anti-tumor responses in mice, Vaccine, 29, 920-930, doi: 10.1016/j.vaccine.2010.11.083.

78. Ferraro, B., Morrow, M. P., Hutnick, N. A., Shin, T. H., Lucke, C. E., and Weiner, D. B. (2011) Clinical applications of DNA vaccines: current progress, Clin. Infect. Dis., 53, 296-302, doi: 10.1093/cid/cir334.

79. Maldonado, L., Teague, J. E., Morrow, M. P., Jotova, I., Wu, T. C., Wang, C., Desmarais, C., Boyer, J. D., Tycko, B., Robins, H. S., Clark, R. A., and Trimble, C. L. (2014) Intramuscular therapeutic vaccination targeting HPV16 induces T-cell responses that localize in mucosal lesions, Sci. Transl. Med., 6, 221ra13, doi: 10.1126/scitranslmed. 3007323.

80. Trimble, C., Lin, C. T., Hung, C. F., Pai, S., Juang, J., He, L., Gillison, M., Pardoll, D., Wu, L., and Wu, T. C. (2003) Comparison of the CD8 $+\mathrm{T}$-cell responses and antitumor effects generated by DNA vaccine administered through gene gun, biojector, and syringe, Vaccine, 21, 4036-4042.

81. Alvarez, R. D., Huh, W. K., Bae, S., Lamb, L. S., Jr., Conner, M. G., Boyer, J., Wang, C., Hung, C. F., Sauter, E., Paradis, M., Adams, E. A., Hester, S., Jackson, B. E., $\mathrm{Wu}$, T. C., and Trimble, C. L. (2016) A pilot study of pNGVL4a-CRT/E7(detox) for the treatment of patients with HPV16+ cervical intraepithelial neoplasia $2 / 3$ (CIN2/3), Gynecol. Oncol., 140, 245-252, doi: 10.1016/ j.ygyno.2015.11.026.

82. Chandra, J., Dutton, J. L., Li, B., Woo, W. P., Xu, Y., Tolley, L. K., Yong, M., Wells, J. W., Leggatt, G. R., Finlayson, N., and Frazer, I. H. (2017) DNA vaccine encoding HPV16 oncogenes E6 and E7 induces potent cell-mediated and humoral immunity which protects in tumor challenge and drives E7-expressing skin graft rejection, J. Immunother., 40, 62-70, doi: 10.1097/CJI. 0000000000000156.

83. Lu, S., Wang, S., and Grimes-Serrano, J. M. (2008) Current progress of DNA vaccine studies in humans, Expert Rev. Vaccines, 7, 175-191, doi: 10.1586/14760584. 7.2.175.

84. Ali, A. A., McCrudden, C. M., McCaffrey, J., McBride, J. W., Cole, G., Dunne, N. J., Robson, T., Kissenpfennig, A., Donnelly, R. F., and McCarthy, H. O. (2017) DNA vaccination for cervical cancer; a novel technology platform of RALA mediated gene delivery via polymeric microneedles, Nanomedicine, 13, 921-932, doi: 10.1016/j.nano.2016. 11.019.

85. Samuels, S., Marijne Heeren, A., Zijlmans, H. J. M. A. A., Welters, M. J. P., van den Berg, J. H., Philips, D., Kvistborg, P., Ehsan, I., Scholl, S. M. E., Nuijen, B., Schumacher, T. N. M., van Beurden, M., Jordanova, E. S., Haanen, J. B. A. G., van der Burg, S. H., and Kenter, G. G. (2017) HPV16 E7 DNA tattooing: safety, immunogenicity, and clinical response in patients with HPV-positive vulvar intraepithelial neoplasia, Cancer Immunol. Immunother., 66, 1163-1173, doi: 10.1007/s00262-017-2006-y.

86. Ostor, A. G. (1993) Natural history of cervical intraepithelial neoplasia-a critical review, Int. J. Gynecol. Pathol., 12, 186-192. 
87. Morrow, M. P., Kraynyak, K. A., Sylvester, A. J., Dallas, M., Knoblock, D., Boyer, J. D., Yan, J., Vang, R., Khan, A. S., Humeau, L., Sardesai, N. Y., Kim, J. J., Plotkin, S., Weiner, D. B., Trimble, C. L., and Bagarazzi, M. L. (2018) Clinical and immunologic biomarkers for histologic regression of high-grade cervical dysplasia and clearance of HPV16 and HPV18 after immunotherapy, Clin. Cancer Res., 24, 276-294, doi: 10.1158/1078-0432.CCR-172335 .

88. Santos, P. M., and Butterfield, L. H. (2018) Dendritic cellbased cancer vaccines, J. Immunol., 200, 443-449, doi: 10.4049/jimmunol.1701024.

89. Santin, A. D., Bellone, S., Roman, J. J., Burnett, A., Cannon, M. J., and Pecorelli, S. (2005) Therapeutic vaccines for cervical cancer: dendritic cell-based immunotherapy, Curr. Pharm. Des., 11, 3485-3500.

90. Ahn, Y. H., Hong, S. O., Kim, J. H., Noh, K. H., Song, K. H., Lee, Y. H., Jeon, J. H., Kim, D. W., Seo, J. H., and Kim, T. W. (2015) The siRNA cocktail targeting interleukin 10 receptor and transforming growth factor-beta receptor on dendritic cells potentiates tumour antigen-specific CD8(+) T-cell immunity, Clin. Exp. Immunol., 181, 164178, doi: 10.1111/cei.12620.

91. Santin, A. D., Bellone, S., Palmieri, M., Zanolini, A., Ravaggi, A., Siegel, E. R., Roman, J. J., Pecorelli, S., and
Cannon, M. J. (2007) Human papillomavirus type 16 and 18 E7-pulsed dendritic cell vaccination of stage IB or IIA cervical cancer patients: a phase I escalating-dose trial, J. Virol., 82, 1968-1979, doi: 10.1128/JVI.02343-07.

92. Brun, J. L., Rajaonarison, J., Nocart, N., Hoarau, L., Brun, S., and Garrigue, I. (2018) Targeted immunotherapy of high-grade cervical intra-epithelial neoplasia: expectations from clinical trials, Mol. Clin. Oncol., 8, 227-235, doi: 10.3892/mco.2017.1531.

93. Mikyskova, R., Indrova, M., Simova, J., Jandlova, T., Bieblova, J., Jinoch, P., Bubenik, J., and Vonka, V. (2004) Treatment of minimal residual disease after surgery or chemotherapy in mice carrying HPV16-associated tumours: cytokine and gene therapy with IL-2 and GMCSF, Int. J. Oncol., 24, 161-167, doi: 10.3892/ijo.24.1.161.

94. Chang, E. Y., Chen, C. H., Ji, H., Wang, T. L., Hung, K., Lee, B. P., Huang, A. Y., Kurman, R. J., Pardoll, D. M., and $\mathrm{Wu}, \mathrm{T}$. (2000) Antigen-specific cancer immunotherapy using a GM-CSF secreting allogeneic tumor cell-based vaccine, Int. J. Cancer, 86, 725-730.

95. Schneider, K., Gronhoj, C., Hahn, C. H., and von Buchwald, C. (2018) Therapeutic human papillomavirus vaccines in head and neck cancer: a systematic review of current clinical trials, Vaccine, 36, 6594-6605, doi: 10.1016/j.vaccine.2018.09.027. 